\title{
SOBRE EL DERECHO CONCEBIDO COMO FENOMENO
}

\section{Andrés Cuneo Macchiavello ${ }^{2}$}

1. Permítanme comenzar con una breve historia. Corría el año 1973 y yo era profesor en la Universidad Católica de Chile. Enseñaba Derecho Civil, ya por algunos años e Introducción al Derecho, por unos pocos menos. Había desarrollado materiales de clase para este último curso, que había logrado madurar y perfeccionar de modo que constituía un resultado que, pensé, podía exponerse a la vergüenza pública de su edición formal. Presentado el texto a la editorial, se decidió su publicación. Se me observó, sin embargo, que el título de mi libro no era excesivamente novedoso. Lo había denominado "Introducción al Derecho".

2. En verdad deben haberse publicado varios miles de textos bajo el título de "Introducción al Derecho". No pude menos que aceptar la crítica de los editores.

3. La búsqueda de una nueva denominación me obligó a repensar acerca de qué pretendía con mi libro. Este ciertamente no constituía una revolución en el pensamiento jurídico; era un texto destinado -así lo veo yo-, a servir para proporcionar la información previa, los casos y los problemas para que un alumno de primer año pueda participar, activamente, en un curso que lo introduzca debidamente al conocimiento de lo jurídico. También se propone que el alumno pueda tomar, al menos de un modo provisional, alguna posición personal sobre las principales cuestiones que plantea el conocimiento del Derecho.

4. La elección del título del texto me recondujo, así, a los objetivos del curso al cual estaba destinado. Se trataba de una asignatura cuyas finalidades básicas se orientaban a que el alumno que se iniciaba en la comprensión del saber jurídico pudiere, más que recibir una serie de conceptos, experìmentarlo y aprehenderlo sin quedar, además, marcado -o prejuiciado- por las concepciones iusfilosóficas de su profesor o de su Facultad de Derecho. Se buscaba, de este modo, respetar la libertad intelectual del alumno para favorecer el desarrollo de sus capacidades críticas.

5. Este curso se ofrecía a alumnos que seguían la carrera de Derecho, pero estaba también abierto a otros que se interesaban por nuestro saber, desde un punto de vista más cultural o complementario a su formación profesional, por ejemplo, alumnos de Ciencia Política, Ingeniería Comercial o Historia.

\footnotetext{
${ }^{1}$ El presente trabajo, corresponde a la conferencia ofrecida por el Profesor Andrés Cuneo Macchiavello, en la Escuela de Derecho de la Universidad Católica del Norte, sede Coquimbo, el día 3 de Octubre de 2003, en el marco "Ciclo de Profesores Invitados", que dicha Escuela ofrece a sus alumnos. 
6. Ello ocurría en tiempos extremadamente críticos en nuestro país -la primera parte de la década de los setenta-, por lo que, adicionalmente, tenía la pretensión de ofrecer una visión del Derecho que permitiera apreciar su relación, pero también su relativa autonomía, frente a los otros fenómenos sociales y su carga de valores provenientes de su función cautelar de la dignidad de la persona humana.

7. Todo lo anterior me llevó al título definitivo del libro: "Materiales para un Estudio del Fenómeno Jurídico", implicando que el objeto de conocimiento relevante era el fenómeno jurídico y que sus contenidos o "materiales", esto es, los casos, lecturas y problemas, tenía por finalidad proporcionar información y motivar la discusión relativa a dicho "fenómeno".

8. La elección de la palabra fenómeno no fue casual, indica una cierta toma de posición del autor frente a lo que considera el objeto del saber jurídico. El Derecho, como disciplina, tiene por finalidad aprehender un ente, tal como se manifiesta en su existencia, esto es, en medio de la sociedad y de su cultura.

9. El Derecho manifiesta su existencia en la realidad social. Es que, como sabemos, sólo hay Derecho en sociedad. Robinson Crusoe, sin bien estaba sujeto a la moral, no es sujeto del Derecho mientras está solo en la isla de Juan Fernández. El Derecho sólo surge cuando llega Viernes, otro ser humano. Como dice un adagio antiguo: Sin sociedad no hay Derecho, sólo hay Derecho alli donde hay sociedad.

10. Estudiar al Derecho como un fenómeno en la sociedad implica tomar conciencia de las variadas dimensiones de su manifestación: como precepto que impera una conducta, como hecho social y como expresión de unas ciertas aspiraciones humanas, acerca de cómo deben ser las relaciones entre los hombres.

11. Tan pronto se comienza a pensar al Derecho como fenómeno, uno descubre lo limitadas que han sido muchas de las percepciones que han dominado, en el análisis jurídico, de los últimos siglos: el iusnaturalismo racionalista del siglo XVIII, el positivismo jurídico y las escuelas sociológicas del Derecho.

12. Llamar limitadas a las percepciones aludidas no significa, con todo, negar su aporte de verdad al conocimiento del fenómeno jurídico. Si las califico así es porque pienso que su visión es válida, pero parcial, para la comprensión de lo que estudiamos. Ahora, cuando ellas pretenden ser la descripción única o pura del Derecho, entonces claramente estamos en el terreno de la falsificación del objeto de conocimiento.

13. Así, por ejemplo, un cierto grado de eficacia en la realidad social es un signo distintivo de lo jurídico que jamás puede estar ausente. Este es un reconocimiento que ha debido hacer, incluso Kelsen, no obstante su aspiración a una ciencia o teoría "puras" del Derecho, purificada de los otros elementos "contaminantes", esto es, lo fáctico y lo valórico. Sólo a partir de, al menos, un mínimo grado de eficacia del ordenamiento como un todo o, de

CUNEO M., Andrés: Materiales para un estudio del fenómeno juridico, Editorial Jurídica de Chile, Santiago, 1974. 
una norma singular, puede reconocerse la existencia del ordenamiento jurídico o de la regla de Derecho.

14. Si observamos al Derecho como fenómeno, y tratamos de despojamos de los posibles preconceptos que podamos tener, llegamos necesariamente a la conclusión que este se manifiesta, a nuestra conciencia, de un modo tridimensional, como algo que es, a la vez, un conjunto de prescripciones de conducta, un hecho socialmente perceptible y la expresión de una cierta opción, eventualmente entre varias posibles, acerca de cómo deberían ser las relaciones de los seres humanos en la sociedad.

15. Cuando digo que me despojo de ciertos preconceptos, estoy postulando que, para conocer al Derecho como fenómeno, tengo que exponerme a él, sin una definición previa, dogmáticamente aceptada, de lo que entiendo por Derecho. Si no lo hago, probablemente, sólo confirmaré mi prejuicio

16. Lo anterior queda de manifiesto por una simple reflexión. Si opto, por ejemplo, por una de las tantas definiciones que ponen su acento en el género norma o mandato y en la diferencia específica de la coercibilidad, sólo reconoceré, como jurídicos, a aquellos fenómenos que se presentan bajo la forma de una prescripción de conducta aparejada de una posible sanción de fuerza, para el caso de incumplimiento. Habré adoptado, entonces, un concepto positivista del Derecho que identificará a este fenómeno sólo como un conjunto de mandatos impuestos -positum-, por quien tiene el control de la fuerza social

17. Se seguirá de lo anterior que me perderé una parte de lo jurídico constituida por las conductas tal como son vividas por la comunidad, con la conciencia de su imperativo jurídico, como ocurre con la costumbre o con el cumplimiento espontáneo de las normas. También omitiré el incumplimiento generalizado de un precepto, en su caso. Perderé, asimismo, la forma como los órganos llamados aplicar el Derecho lo entienden, y por tanto lo aplican. Prescindiré, finalmente, de toda consideración respecto de los fines o valores del Derecho, situación que me impedirá distinguir entre lo que es una simple imposición del poder político y el establecimiento de una verdadera norma jurídica.

18. Otro tanto sucederá si mi acento queda puesto exclusivamente en los fines o valores, lo que me llevará a privar de su condición jurídica, sin más, a aquellas prescripciones de conducta social que pueden estar promulgadas, socialmente vigentes e impuestas por el poder político, pero que niegan, en todo o en parte, algún valor jurídico fundamental.

19. Igualmente mi aprehensión de lo jurídico será trunca o simplemente imposible si mi foco de observación se restringe a los simples usos y prácticas sociales.

20. Avancemos un poco más en cada una de estas vertientes de lo jurídico.

KELSEN, Hans: Teoria Pura del Derecho, 23ª edición, Editorial Universitaria de Buenos Aires, Buenos Aires, Mayo de 1986, página 142 y ss. 
21. No puedo negar que el Derecho se manifiesta, a nuestra conciencia, de súbdito, obligado u observado, primariamente una como norma -incluso independientemente de su expresión formal: si legislada o consuetudinaria-, esto es, como un imperativo de conducta formulada bajo una amenaza de sanción.

22. Creo que esta percepción inicial es la que ha encandilado a los positivistas. Digo encandilado porque, al igual que una luz muy fuerte, se impone a toda otra imagen e impide ver las otras realidades que debe captar nuestro campo visual, así a los positivistas el encandilamiento les ha impedido preguntarse si dicha norma efectivamente se traduce en actos de acatamiento, en vida social y si ella expresa o no valores apreciados por sus destinatarios.

23. Incluso el énfasis en lo normativo hace perder de vista que también, dentro del tejido jurídico positivo, podemos encontrar principios no formulados como normas, pero que son igualmente criterios para valorar conductas, o decidir sobre las consecuencias de hechos o actos jurídicos.

24. El Derecho es, ciertamente, normas y también principios, impuestos, en su origen y en su aplicación, por el poder público. Pero no sólo normas y principios.

25. Un ordenamiento que es incapaz de imponerse en un territorio dado, una norma que es generalmente evadida o no acatada por los ciudadanos, un precepto que es sistemáticamente omitido en su aplicación por los jueces, podrán tener toda la apariencia formal de lo jurídico pero, en verdad, no constituyen Derecho.

26. Así, muchas normas todavía formalmente vigentes en parte o recientemente derogadas que en nuestro Código Penal, que sancionan seriamente, con penas corporales, no han tenido, desde hace mucho tiempo, mayor aplicación ya que no han resistido la erosión del cambio en las costumbres y las valoraciones sociales. ¿Quién conoce de alguna sentencia recientemente dictada, sancionando por la comisión del rapto de una doncella mayor de doce años y menor de dieciocho, ejecutado con su anuencia (Código Penal artículo 359, sólo derogado por la ley 19.617 de Julio de 1999)?. A juzgar por la jurisprudencia publicada, las últimas corresponden a los años 1914 y 1925. ¿Quién pude darnos noticia de una sentencia por el delito de estupro, esto es tener relación sexual con una doncella mayor de doce años y menor de dieciocho, mediando engaño (artículo 363 del Código Penal, en su redacción anterior a la referida ley 19.617)?. Las últimas jurisprudencias publicadas sobre la materia corresponden a los años 1911 y $1932^{5}$.

27. También, en algún momento, sin darnos cuenta - $y$ esto no envuelve, por mi parte, ningún juicio de valor-, el empleo de los gastos reservados de que disponen algunos funcionarios del Estado, pasó a ser una forma aceptada de mejorar los ingresos de otros altos funcionarios cuya remuneración legalmente asignada era enteramente absurda. Así lo reconocieron los

Ver: Repertorio de Legislación y Jurisprudencia Chilenas. Código Penal: Editorial Juridica de Chile, Santiago, 1925. 
tribunales. Y esto en un ámbito que, por ser de Derecho Público, sólo se puede hacer lo que está permitido expresamente.

28. No deja de llamar la atención todo lo que he señalado ya que no existe, en nuestro ordenamiento, ninguna norma que consagre al desuso como un procedimiento de derogación de la ley.

29. Hoy, de manera uniforme nuestros tribunales, reconociendo el fenómeno de la inflación, fallan disponiendo el reajuste de las obligaciones. Ello ocurrió primeramente en el campo de la responsabilidad extracontractual y luego de las obligaciones emanadas de contrato. Lo mismo ocurre y, con igual secuencia, en relación al llamado daño moral, esto es, el experimentado por las personas en forma de depresión o sufrimiento, cuando son consecuencia del hecho ilícito de un tercero.

30. No ha habido, en relación a la materia (salvo en aspectos puntuales), cambio alguno en la legislación que permita proceder del modo que lo hacen nuestros jueces. Los textos en que ellos se apoyan usualmente vienen de la época del Código Civil, cuando ni la inflación ni el daño moral formaban parte del paisaje jurídico.

31. Pienso que sólo podemos conocer, con certeza, el verdadero contenido de una disposición jurídica a través del testimonio de su aplicación, esto es, conociendo la forma como ha sido empleada por los órganos jurisdiccionales o vivida en la sociedad. Hasta tanto ello no ocurra, la norma promulgada y publicada no es sino un proyecto, más o menos específico, del Derecho que va a ser.

32. En lo singular de las relaciones interpersonales, el Derecho, por definición es declarado por los jueces. Ese es el rol que corresponde a la función jurisdiccional. El componente de hecho de las contiendas es el que permite fijar, en forma definitiva, el sentido de la norma.

33. En lo social, la aceptación, el acatamiento o el rechazo de la norma por parte de sus destinatarios y agentes jurídicos también constituyen una variable de su éxito, es decir, de su capacidad de introducir efectivamente un cambio en las conductas sociales. En una medida muy importante, la eficacia de un precepto está dada por su cumplimiento espontáneo. Difícilmente la vigencia de un precepto o del ordenamiento jurídico, en su conjunto, pueden descansar, exclusivamente, en la pura fuerza del poder público. Esto último sólo ocurre con los regímenes de terror.

34. En síntesis, quien sólo busca al Derecho en los libros de leyes jamás tendrá la plenitud de la información indispensable para contestar las preguntas que clásicamente se hacen al jurista: ¿cuál es el Derecho?, o ‘cuál es mi derecho?

35. Desde el momento que abandonamos la noción de que el Derecho es puramente norma impuesta por el poder político y que su capacidad de transformarse en conducta efectiva no es incondicionada, se empieza a abrir campo la pregunta de la legitimidad de la norma promulgada, es decir, si acaso ella es el mejor Derecho que podría existir, si tiene o no la aptitud para 
suscitar la lealtad de los órganos llamados a su aplicación y si cuenta con la posibilidad de una adhesión, más o menos espontánea, de sus destinatarios.

36. Surge así la cuestión de los valores o fines de la norma y, con ella, una tercera perspectiva para completar el ámbito existencial del fenómeno jurídico. $\mathrm{La}$ pregunta que ilustra sobre este componente del fenómeno es, de este modo, la siguiente: ¿La norma, para ser Derecho puede ser de cualquier modo o debe ser necesariamente de una manera determinada?

37. En mi texto de materiales sobre el Fenómeno Jurídico pongo el ejemplo siguiente: Supongamos que, en una cierta sociedad se promulgara, de acuerdo a sus reglas constitucionales, una ley que dispusiera que todos los habitantes, dentro del radio urbano de sus ciudades, deben caminar sobre sus manos. ¿Sería ésta una norma jurídica?

38. El ejemplo es extremo y caricaturesco, pero ilustra sobre una limitación de los contenidos posibles del Derecho. Este no puede disponer que la conducta humana sea contraria a la naturaleza de las cosas. Los pies están hechos para caminar, no así las manos. El Derecho no puede ser de cualquier modo. Hay también un deber ser para el Derecho. Lon Fuller -filósofo del Derecho norteamericano-, ilustra este punto en una obra breve y muy acertadamente titulada: "La Moral del Derecho" (Editorial F. Trillas S.A. México, 1967).

39. Aparece, de este modo, ante nuestra contemplación del fenómeno, su dimensión finalista o valórica, según como queramos llamarla. El precepto jurídico impera una conducta como debida, pero este imperativo sólo obliga en la medida que conscientemente pueda asociarse a lo justo. Puede ser que debamos obedecer una norma injusta, por temor a la sanción, pero tal mandato, frente a una conciencia generalizada de su ilegitimidad esta llamado, más tarde o más temprano, a peder su eficacia.

40. Con todo, las diversas percepciones acerca de lo justo, que ciertamente existen entre los hombres, han desalentado a muchos en la búsqueda del Derecho justo o, al menos, más justo. Ello explica el escepticismo con que muchos pensadores abordan el tema y que los ha llevado a excluir del ámbito del Derecho a la cuestión de la Justicia, relegándola al campo de la ideología.

41. Legaz y Lacambra ${ }^{6}$, nos da, sin embargo, una guía esperanzadora en este punto: existen numerosos ideales de justicia y una sola idea de lo justo. Los ideales son nuestra percepción subjetiva del valor de lo justo, la que suele variar significativamente de individuo en individuo; la idea de lo justo es lo justo en sí: el verdadero deber ser del Derecho. Los ideales de lo justo suelen ayudarnos a reconocer la idea de lo justo, pero no hay garantía de que siempre ocurre así.

42. Nuestra historia nacional reciente no proporciona un caso en que los ideales han conducido a la idea de justicia. ¿Hay alguien, hoy, que podría postular que el ser humano, en cuanto tal, no está investido de una dignidad y

\footnotetext{
LEGAZ Y LA CAMBRA, Luis: Introducción a la Ciencia del Derecho, Editorial Bosch, Barcelona, 1943.
} 
derechos que le son propios e inalienables y que el derecho positivo no puede desconocer?

43. Es muy posible que algunos lleguemos a tal conclusión porque pensamos que el hombre, por naturaleza, está dotado de tales atributos ( $y$, dentro de estos últimos, algunos pensamos, además, que ello responde a la voluntad creadora de Dios). Hay otros que han adoptado tal posición porque la evolución de nuestra cultura los ha llevado a estimar al ser humano, sin distinción, como lo más valioso de lo existente. Hay otros, en fin, que por su propia y dolorosa experiencia, han descubierto que el único contrapeso al poder absoluto es el juicio ético de sus mandatos.

44. Los planteamientos antes descritos responden a percepciones subjetivas distintas, pero demuestran, a mi juicio, que por diversos caminos, podemos llegar al conocimiento de una realidad superior a los mandatos coercitivos y a las vivencias de la sociedad. Así ocurre con los valores o fines del Derecho. Sin tal componente el pretendido precepto jurídico no pasa de ser una ficción, una apariencia, o una práctica eventualmente extendida, aunque moralmente reprobable.

45. Con todo, si observamos, con una cierta mirada histórica, como se ha plateado en Occidente la cuestión de los fines del Derecho, creo que debemos reconocer que todos hemos exagerado un tanto. Reflexionemos entre dos de los valores o fines preponderantes: la seguridad y la Justicia. El positivismo ha apostado siempre por la seguridad. El iusnaturalismo -en sus diferentes versiones-, por la justicia.

46. Debo confesar mi sospecha que la ausencia de abogados (o juristas), en esta discusión, ha sido una de las causas de su radicalización. Los protagonistas de este debate han sido principalmente filósofos, moralistas o politólogos.

47. Los abogados sabemos que lo peor de todo es la inseguridad. Muchas veces estamos dispuesto a aceptar un cierto grado de injusticia, en nuestra soluciones y hasta en las disposiciones impuestas por el poder político, ya que sabemos que más injusto y dañino que una norma insuficientemente justa puede resultar la falta absoluta de todo precepto. Por otro lado sabemos también que un grado importante del éxito -llamémoslo eficacia-, de una disposición depende, en buen medida, de su cumplimiento espontáneo y, por ende, de su aceptación.

48. Un mínimo de seguridad es, entonces, una exigencia de la propia Justicia. Ella es, probablemente la más elemental de las exigencias para que algo pueda ser estimado como un precepto jurídico. El saber que estoy del todo desprotegido es, al menos, un grado elemental de seguridad y certidumbre a las cuales tengo derecho por exigencia de la Justicia. Por ello no es fácil encontrar un ejemplo de norma que podamos de calificar -si se pudiera-, de cien por ciento injusta $y$, con mayor razón, un ordenamiento jurídico completo, por más aberrante que sea, que pudiera recibir igual calificación.

49. La cuestión que nos toca resolver a los abogados (o juristas) es qué grado de injusticia puede tolerarse a fin de tener un precepto o un ordenamiento 
seguros, dignos de ser calificados como jurídicos. No podemos calificar como jurídica la orden de Herodes de matar a todos los niños menores de dos años que había en Belén, para asegurar su sucesión dinástica (Mt. 2:16), porque no pasa, ciertamente, el examen de lo justo. Con todo, no podemos descalificar, por injusta, la norma del artículo $8^{\circ}$ del Código Civil que dispone que "Nadie puede alegar la ignorancia de la ley después que esta haya entrado en vigencia", aunque en muchos casos, a veces dramáticos, nos consta que no pasa de ser una ficción. Un mínimo de seguridad exige de este precepto.

50. La presencia de abogados en el debate habría podido ayudar también con el aporte que consiste en que el verdadero sentido de las normas no se halla en su formulación abstracta, sino que en su fase de aplicación y que, por tanto, el grado definitivo de justicia o injusticia sólo se puede estimar cuando el precepto se intenta aplicar a una situación de hecho. Con esta mirada se podría descubrir que, en muchos casos, quien está llamado a aplicar tiene la posibilidad de elegir más de una interpretación, a partir de un mismo texto normativo, y que alguna de estas interpretaciones podría evitar los aparentes efectos perversos del texto o de la propia intención de su autor.

51. Esa misma presencia podría contribuir al convencimiento de que la idea de justicia se relaciona con la de igualdad, pero que ésta debe apreciarse en concreto, oportunidad en que surge el rol de la equidad, que permite hacer justicia, como dice Aristóteles, rectificando las injusticias que la generalidad de la norma puede ocasionar en su aplicación a un caso particular.

52. Seguridad y Justicia (y con ella la equidad), son fines o valores que debe encarnarse en el Derecho.

53. En fin, norma, conducta y valor son los componentes indispensables de cada una de las manifestaciones del Derecho visto como un fenómeno en la sociedad.

54. Volvamos a mi texto de materiales. Relacionándolo con todo lo dicho debo hacer explícito que mi libro fue construido con una triple finalidad.

55. La primera es mostrar a los alumnos, a quienes está dirigido, que el Derecho es un objeto de conocimiento complejo, constituido por diversos elementos: norma, conducta social y valor. La significación o relevancia individual que se asigna a cada uno de ellos redunda en el concepto mismo que se pueda tener acerca del Derecho. Es obvio, por ejemplo, que el concepto será diverso entre quienes sólo reconocen a la coercibilidad como signo distintivo de lo jurídico y quienes exigen a la norma ser, además, expresión de la Justicia.

56. Fue también elaborado con la idea de respetar la libertad intelectual de los alumnos, ya que el texto les permite su propia opción, mediante la aceptación o rechazo ilustrados, de uno o más de los componentes del fenómeno jurídico, como integrantes de la idea de Derecho. Esto les permite optar conscientemente por ser positivista, ius naturalista, de acuerdo a alguna de sus vertientes, o partidario de la escuela sociológica del Derecho, etc. 
57. La tercera de las finalidades fue no falsear la concepción jurídica del propio autor del texto, quien estima que para reconocer un precepto como jurídico, este debe pasar la triple prueba de su vigencia formal, de su vigencia social y de su justicia. Para mí, para que una norma pueda ser legítimamente calificada de norma jurídica, precisa haber sido debidamente puesta en conocimiento de aquellos a que va dirigida, debe ser efectivamente aplicada y acatada en la sociedad y debe constituir un medio para obtener fines sociales adecuadamente combinados en los que la seguridad, el bien común y la Justicia reciben, cada uno su debida ponderación. 